\title{
A STUDY ON THE ACTIVATION OF CAR-SHARING THROUGH THE ANALYSIS OF CITIZEN'S PERCEPTION BASED ON EXPERIENCE: FOCUSING ON BUSAN, SOUTH KOREA
}

\author{
JONGJU HA, HUNYOUNG JUNG, HYERYEONG LEE \& MINHYE CHOI \\ Department of Urban Planning and Engineering, Pusan National University, South Korea
}

\begin{abstract}
A car-sharing system is being introduced to Korea and its application has been mainly accommodated by the private sector. As conflicts with the government's regulations on transportation industries seems to interrupt the expansion of the services, the involvement of the public sector in taking the initiative is necessary. Accordingly, the perception of the citizens, who are the drivers of the operations, as well as the participants in policy implementation, must be examined. In this research, a plan to revitalize the shared transport was explored by closely examining the citizen's perception on car-sharing, using the data conducted through an online survey of 500 people. The research took place in Busan, a metropolitan city with a population of about 3.4 million, where the involvement of public sector on carsharing operations is significantly lacking. First, an importance-performance analysis was performed on the responses that had experienced car-sharing in the past. The result confirmed that the ways to reserve, pick-up/return, and the cost were the important factors on the user satisfaction. Second, we employed binary logistic regression based on the Stated Preference survey technique on the responses that had not experienced car-sharing, but with the intention to use car-sharing in the future. As a result, the probability of choosing car-sharing decreased as the cost and wait time increased. In particular, it has been found that returning a vehicle at a desired place is more than four times preferred than returning at the rented location. Based on the analysis, we concluded that the active engagement of the public sector is necessary in improving the efficiency of operations, such as the provisions on potential pickup/return spots available for private operators, and policy implications to ease the regulatory standards. Keywords: car-sharing, shared transportation, importance-performance analysis, binary logistic regression, passenger car use.
\end{abstract}

\section{INTRODUCTION}

Many issues arise when it comes to transportation in the city, as the use of personal passenger cars is growing day by day. In an effort to resolve these issues, policies oriented towards public transportation and to control transportation demand have been introduced. However, the use of personal passenger cars is growing because of its many benefits such as convenience and comfort.

Sharing transportation has emerged as a solution to reduce the amount of personal passenger car usage. Car-sharing is a well-known door-to-door service that has been introduced and used not only for research, but also for the actual policy.

The first car-sharing system goes back to a used-car sharing service started in Zurich, Switzerland in 1948. It didn't get much attention until the 1990's when a variety of sharing programs were introduced thanks to Europeans' perception change about using cars and the development of information and communication technology [1]. In North America, 40 car sharing programs have been launched since 1994 and they have witnessed growing market shares and users [2].

It has already been proven that car-sharing actually reduces the frequency of personal car usage and VKT (Vehicle Kilometers Traveled) [3]. Also a study was conducted that found 
the intention of owning personal passenger cars decreased after using car-sharing services [4].

Electric vehicles are gaining ground in car-sharing programs in the city [5] and various studies on the many different types of car sharing services are being conducted based on studies about the adaptability of the state-of-the-art technology a.k.a. the early adopters [6]. Now car-sharing service is a much-appreciated transit system all over the world.

In 2011, GreenCar, a private car-sharing service, was launched in Seoul, the capital city of Korea. In public areas, a sharing service policy called Seoulnanumcar, a sharing transit service based on the business agreement between private companies and public institutes in the Seoul metropolitan area, started their service in 2013 [7]. As of 2016, it has 1,348,402 members, 1,438 stations with 4,003 cars and 5,956 people who have used this service [8].

There are a variety of on-going studies about car-sharing in Korea. As a result of user behavior analysis on car-sharing in Suwon, a city located in Seoul's metropolitan area, the easy access to the bus does affect the car-sharing service, whereas access to the greater area's railway does not [9]. The user behaviour analysis, based on the user's records of car-sharing services from Incheon Metropolitan City in 2016, showed that more people have used the service in areas where many passengers get on and off their public transportation and in residential areas with a high ratio of gross area [10]. Research on P2P car-sharing and donation of personally owned car was conducted with 200 people living in an apartment complex in Seoul. It manifested that people with less family members who own more cars than others tend to be positive about the car-sharing service [11].

Most of these studies are being conducted in the Seoul metropolitan area. This is the only area that provides car-sharing services through business agreement between the public and private sectors. In other areas, there are car-sharing services, but it is provided mostly by private companies. Even cities located within the Seoul metropolitan area that have business agreements between private and public sectors, have a more actively engaged private sector. Recently, conflicts between Korean transportation laws, car-sharing services and the existing taxi industry have been getting more serious. This was somewhat inevitable because the taxi industry is well developed in Korea and it clashes with car-sharing, a new-comer in the business. Therefore, it requires leadership from the public sector in policies.

For the successful introduction of car-sharing services as a solution for city transit issues, it is imperative that the perception of citizens be studied because people are the main consumers of personal passenger cars and would be the major participants of these policies. After such studies the appropriate systems should be adopted accordingly.

Therefore, this study will look into the perception of Korean citizens about car-sharing in an effort to find a way to revitalize shared transportation. Based on the results of this study, detailed solutions to boost shared transportation, dependent on the users' experience, will be further contemplated.

\section{METHOD}

This study will investigate citizens' perceptions of car-sharing services, which are considered typical examples of sharing transportation, based on their experience of using the service. It will also contemplate solutions to revitalize shared transportation in a way that helps to relieve transit problems in the city. Busan was selected as the appropriate subject place for this study because it is a big city with active car-sharing services available in the private sector. However, its public sector is not driven to lead this service.

Previous studies and documents related to shared transportation were thoroughly reviewed and based on this review, the question items were prepared through discussions before a survey was conducted. Utilizing the data collected by the survey, an analysis on the 
importance and satisfaction (IPA) of using car-sharing services was carried out for the respondents who have already used this service.

For the respondents who have not used the car-sharing service but have the intention to use the service in the future, the influence factors on the use of car-sharing services were examined with Binary Logistic Regression based on SP (Stated Preference). Taking all of these reviews into account, ideas to boost shared transportation were reviewed dependent on cases with and without the actual experience of using the service.

\section{SURVEY}

\subsection{Importance of the survey}

In order to suppress the growing use of personal passenger cars, which is the main cause of transit problems in the city, car-sharing services providing door-to-door service to the users must be considered as an option. The car-sharing service market is fast growing in Korea, however, it would be no different from the existing rent-a-car service if the public sector is not driven to lead. Therefore, it is necessary to define the proper roles of the public sector.

In cities where their public sectors failed to take an initial role in pursuing shared transportation services, it is urgent to come up with policies that meet the purpose of carsharing services and pursue the public interest simultaneously. First of all, it is important to acquire basic information related to revitalization of shared transportation by looking into people's perceptions on sharing services and their willingness to use the service in the future. Therefore, a survey must be conducted with regard to car-sharing services.

\subsection{Survey questionnaire}

The survey questionnaire consists of following two directional steps to analyse respondents' experiences with and without using the service. First, the perception of respondents who have used the car-sharing service before were looked at and, through numerous discussions between researchers, Table 1 was prepared to measure the level of importance and satisfaction by utilizing the Likert 7-point scale.

Next, using SP modelling, which is widely used to study some services not currently being used, variables and levels of each variable for Table 2 were generated to analyse the influence factors on the future usage of car-sharing services for those who have not used the service.

According to the hourly rate for SoCar's Hyundai Avante, a private car-sharing company, approximately KRW 8,000 won is set as standard, including 4,350 won for the average one hour rental fee and 3,600 won for fuel under the condition of driving $20 \mathrm{~km}$. To this standard, a $25 \%$ discount and rate increase were applied in three levels such as 6,000, 8000 and 10,000 won from Table 2.

The time elapsed to rent a car was set in three levels in Table 2 with five minute intervals for each level. Finally, for returning the vehicle, another three levels were set. These included categories such as returning to the place where the car was rented, returning rented car to renter's desired location and picking-up the vehicle by the car-sharing company.

There can be 27 possible cases under the conditions set with three variables and three levels. However, it would be difficult for respondents to answer about all possible cases, so this study came up with nine different scenarios by using the table of orthogonal arrays as specified in the experiment's design to ask about items in using the car-sharing service. 
Table 1: Question items about car-sharing services.

\begin{tabular}{|c|c|c|c|}
\hline No. & Question item & No. & Question item \\
\hline $\mathbf{1}$ & Renting a car (rent) & $\mathbf{6}$ & Variety of cars \\
\hline $\mathbf{2}$ & Returning a car & $\mathbf{7}$ & PR of car-sharing \\
\hline $\mathbf{3}$ & Reserving and using a car & $\mathbf{8}$ & Discount policies \\
\hline $\mathbf{4}$ & Cleanliness of the car & $\mathbf{9}$ & $\begin{array}{c}\text { Incentives for using car-sharing } \\
\text { services such as tax benefits, etc. }\end{array}$ \\
\hline $\mathbf{5}$ & Cost of using the service & $\mathbf{1 0}$ & $\begin{array}{c}\text { Connectivity to public } \\
\text { transportation such as buses and } \\
\text { subways }\end{array}$ \\
\hline
\end{tabular}

Table 2: Variables and levels of SP question items.

\begin{tabular}{|c|c|c|c|}
\hline \multirow{2}{*}{ Variables } & \multicolumn{3}{|c|}{ Level } \\
\cline { 2 - 4 } & $\mathbf{0}$ & $\mathbf{1}$ & $\mathbf{2}$ \\
\hline Hourly rate & 6,000 won & 8,000 won & 10,000 won \\
\hline $\begin{array}{c}\text { Elapsed time } \\
\text { to rent a car }\end{array}$ & $5 \mathrm{~min}$. & $10 \mathrm{~min}$. & $15 \mathrm{~min}$. \\
\hline $\begin{array}{c}\text { Returning } \\
\text { the vehicle }\end{array}$ & $\begin{array}{c}\text { To the place where } \\
\text { the car was rented }\end{array}$ & $\begin{array}{c}\text { To the renter's desired } \\
\text { location }\end{array}$ & $\begin{array}{c}\text { Pick-up by the car- } \\
\text { sharing company }\end{array}$ \\
\hline
\end{tabular}

Table 3: Summary of the survey.

\begin{tabular}{|c|c|}
\hline Item & Contents \\
\hline Research subject & Citizens of Busan \\
\hline Research period & June $11,2018 \sim$ June 17,2018 \\
\hline Survey period & Online survey \\
\hline The number of surveys & 500 \\
\hline Valid number of surveys & 500 \\
\hline
\end{tabular}

\subsection{Summary of the survey}

Table 3 shows the summary of the survey in this study. This survey was conducted online during a one-week period in June 2018 for the citizens living in Busan. There were 500 surveys conducted and they were all carried out with valid responses and all used for the analysis. For the gender proportion, 325 men (65\%) and 175 women (35\%) responded. According to age groups, $12.2 \%$ of respondents were in their $20 \mathrm{~s}, 27 \%$ were in their $30 \mathrm{~s}$, $29.4 \%$ in their $40 \mathrm{~s}, 25.2 \%$ in their $50 \mathrm{~s}$ and $6.2 \%$ in their $60 \mathrm{~s}$ or older.

When they were asked whether they already have used car-sharing services, 101 respondents, about $20.2 \%$ of the total respondents, answered that they have. Another 281 respondents $(56.2 \%)$ who have not used the service answered that they intend to use the service in the future, whereas 118 respondents $(23.6 \%)$ said that they would not use the service. 


\section{ANALYSIS ON THE PERCEPTION DEPENDS ON CAR-SHARING SERVICE EXPERIENCE}

\subsection{Analysis on the level of importance and satisfaction from the} respondents who used the car-sharing service

For the respondents' group who has already used the service, the level of importance and satisfaction were examined for the items listed on Table 1 by using the Likert 7-point scale. Table 4 shows the average points of respondents with seven as the highest point. Analysis on the level of importance and satisfaction with median values from the average points was presented in Fig. 1.

Quadrant 1 shows items such as reservation, return and cleanliness of a car. It turned out that users of the service considered these items to be very important and they showed a high level of satisfaction from the actual question items. Therefore, it is necessary to keep high levels of satisfaction for these items.

Rate and discount items are positioned in quadrant 2. Existing users think that these items are important, however, it tells us that they're not satisfied with the current situation. Hence, coming up with improvement plans on rates and discounts is required.

In quadrant 3 , items such as tax benefit and incentives, transfer connectivity with public transportation, and PR for using car-sharing services are allocated. These are the items considered either as unimportant or dissatisfying, so they are considered low priorities in terms of the policies and marketing. However, it is necessary to pay attention to the fact that respondents gave the lowest points to the transfer connectivity. For the sake of boosting shared transportation through car-sharing services, it is imperative that the perception of users be changed by raising the level of satisfaction in transferring between other forms of transportation.

Table 4: Level of importance and satisfaction from using car-sharing services.

\begin{tabular}{|c|c|c|}
\hline Item & Importance & Satisfaction \\
\hline Renting a car & 5.37 & 4.71 \\
\hline Returning a car & 5.44 & 4.44 \\
\hline Reserving a car & 5.56 & $\mathbf{4 . 8 0}$ \\
\hline Cleanliness & 5.43 & 4.13 \\
\hline Rate & $\mathbf{5 . 8 0}$ & 3.96 \\
\hline Type of vehicles & 4.80 & 4.11 \\
\hline PR & 4.19 & 4.05 \\
\hline Discounts & 5.39 & 3.79 \\
\hline Incentives & 5.24 & 3.49 \\
\hline Transfer & 5.17 & 3.40 \\
\hline connectivity & 5.24 & 4.09 \\
\hline Average & 5.38 & 4.08 \\
\hline Median value & & \\
\hline
\end{tabular}




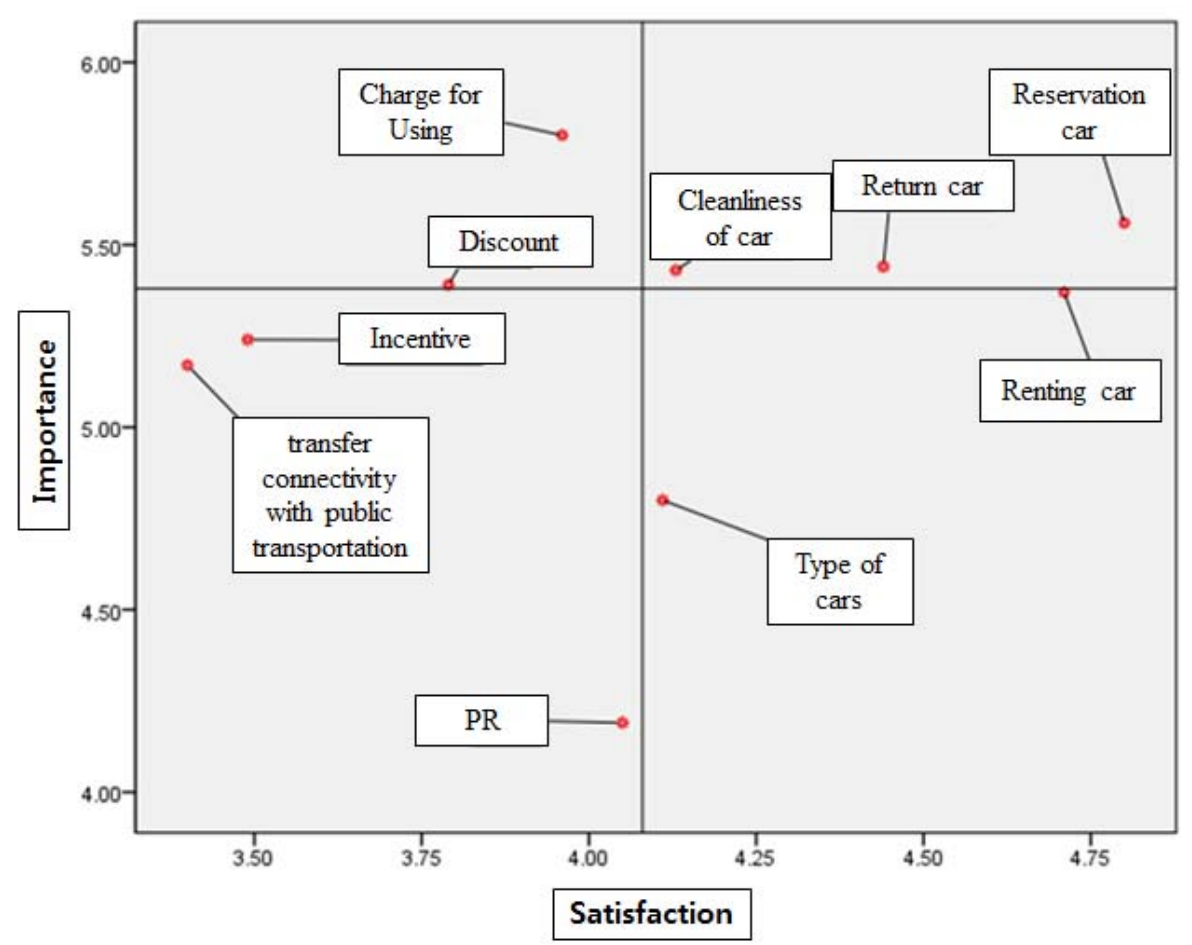

Figure 1: Analysis on the level of importance and satisfaction from using car-sharing.

Both renting and types of cars appear in quadrant 4. People considered the types of cars as relatively not important. Although renting a car is located in quadrant 4 , it is very close to the border of quadrant 1 . Therefore, it is necessary to keep this item, along with the items near in quadrant 1.

\subsection{Analysis on the influence factors of car-sharing for those who}

have not used the service

The influence factors for car-sharing services were examined for the 399 people who have not use the service. Of those, 281 people showed willingness to use the service in the future.

Scenarios were prepared using SP research and they were used to ask binary questions such as, "To use a car-sharing service" and, "Not to use a car-sharing service". This is the reason why a binary logistics regression analysis predicting the probability of relevant events was considered as a more appropriate method in comparison to a normal regression analysis.

Binary logistic regression analysis is linear against the probability logit. Hence it forms following formula and $\pi(\mathrm{x})$ increases or decreases depending on the function of the curve $\mathrm{X}$ in $\mathrm{S}$ shape

$$
\begin{gathered}
\log y[\pi(x)]=\log \left(\frac{\pi(x)}{1-\pi(x)}\right)=\alpha+\beta x, \\
\log y[\pi(x)]=\frac{\exp (\alpha+\beta x)}{1+\exp (\alpha+\beta x)} .
\end{gathered}
$$


Based on this, the odds ration can be extracted by following eqn 3. The odds ratio is an index that indicates how high the probability is whether $\mathrm{x}$ will select a dependent variable as it increases by one step according to the interaction formula in the exponential function. It is very useful to interpret the logistic regression analysis

$$
\frac{\pi(x)}{1-\pi(x)}=\exp (\alpha+\beta x)=e^{\alpha}\left(e^{\beta}\right)^{x} .
$$

The variables inserted to do logistic regression were explained in Table 5. Table 6 shows the result of the set model.

Cox and Snell $R^{2}$, the scale of explanation for the model, shows 0.162 which is relatively low. However, the chi-square value and log-likelihood are valid, and all independent variables are under 0.05 of the level of significance. Hence, analysis was conducted.

Table 5: Explanation of variables.

\begin{tabular}{|c|c|c|}
\hline Variable & Name of variable & Explanation \\
\hline $\begin{array}{l}\text { Dependent } \\
\text { variable }\end{array}$ & Intention to use car-sharing & $0=$ No, $1=$ Yes \\
\hline \multirow{5}{*}{$\begin{array}{c}\text { Independent } \\
\text { variable }\end{array}$} & Fare & $6,8,10$ (unit: 1,000 won) \\
\hline & Elapsed time to rent a car & $5,10,15$ (unit: minute) \\
\hline & $\begin{array}{l}\text { Returning a car } \\
\quad \text { (dummy) }\end{array}$ & $\begin{array}{l}0=\text { to the place where the car was rented } \\
1=\text { to the renter's desired location } \\
2=\text { pick-up by the car-sharing company }\end{array}$ \\
\hline & Usual driving distance & Continuous (unit: km) \\
\hline & Age & $\begin{array}{c}1=20 \mathrm{~s}, 2=30 \mathrm{~s}, \begin{array}{l}3=40 \mathrm{~s}, 4=50 \mathrm{~s}, 5=60 \mathrm{~s} \\
\text { older }\end{array}\end{array}$ \\
\hline
\end{tabular}

Table 6: Results of the binary logistic regression model.

\begin{tabular}{|c|c|c|c|c|c|c|}
\hline \multicolumn{2}{|c|}{ Variables } & $\beta$ & S.E. & Wald & $P$ value & Odds ratio \\
\hline \multicolumn{2}{|r|}{ Rate } & -0.415 & 0.029 & 205.865 & 0.000 & 0.661 \\
\hline \multicolumn{2}{|c|}{$\begin{array}{l}\text { Elapsed time to rent a } \\
\text { car }\end{array}$} & -0.036 & 0.011 & 10.099 & 0.001 & 0.965 \\
\hline \multirow{3}{*}{$\begin{array}{c}\text { Returning } \\
\text { the car }\end{array}$} & \begin{tabular}{|c|} 
To the place \\
where the car \\
was rented \\
\end{tabular} & \multicolumn{2}{|c|}{$\begin{array}{c}- \\
\text { (Reference) }\end{array}$} & 189.868 & 0.000 & \\
\hline & $\begin{array}{c}\text { To the } \\
\text { location the } \\
\text { driver wants }\end{array}$ & 1.489 & 0.120 & 153.778 & 0.000 & 4.431 \\
\hline & $\begin{array}{c}\text { Pick-up by the } \\
\text { car-sharing } \\
\text { company }\end{array}$ & 1.484 & 0.119 & 155.895 & 0.000 & 4.410 \\
\hline \multicolumn{2}{|c|}{ Driving distance } & -0.009 & 0.003 & 9.967 & 0.002 & 0.991 \\
\hline \multicolumn{2}{|c|}{ Age } & 0.160 & 0.041 & 15.323 & 0.000 & 1.174 \\
\hline \multicolumn{2}{|c|}{ Constant terms } & 1.663 & 0.309 & 29.011 & 0.000 & 5.276 \\
\hline
\end{tabular}


Estimation of the rate was extracted as -0.0415 , showing the general tendency that people do not use car-sharing services as the number goes up in the price tag. Negative parameters on the elapsed time to rent a car tells us that the more time it takes to rent a car, the fewer users will likely use this service.

For returning a car, it shows that users like selecting the location they want (1.489) or getting their car picked-up by the car-sharing company (1.484) rather than going to the place where the car was rented. Notably, the probability of using car-sharing services gets 4.431 times higher in the case where users can return the car where they want rather than return it to the place the car was rented.

An explanation of the usual driving distance shows a continuous variable because it needs direct input from the respondents. It shows the tendency that the farther the distance, the fewer the people who want to use the service. An estimation of this analysis was computed as -0.009 . The parameter from the age of respondents is 0.160 , showing that more people want to use this service as they get older.

\section{STUDY ON THE REVITALIZATION OF SHARED TRANSPORTATION}

\subsection{Comparison of perceptions in using car-sharing services in the future}

Table 7 shows three different groups such as group (A), people who have not used the carsharing service but are willing to use the service in the future; group B, people who have not used the service and never will; and group (C), people who have used the service before. The table shows the average between these three respondent groups for the question items designed to measure the influence factors on their intention to use the service in the future. Group A shows relatively high average scores overall for question items. However, group B, which has no intention of using the service in the future, shows relatively low scores, below average, for all question items compared to other groups.

Among other groups, group A - people who have not used the car-sharing service but are willing to use the service in the future - shows the most positive attitudes toward car-sharing

Table 7: Average perception scores of the 3 groups for using car-sharing.

\begin{tabular}{|c|c|c|c|c|}
\hline $\begin{array}{c}\text { Question item } \\
(\mathrm{N})\end{array}$ & $\mathrm{A}$ & $\mathrm{B}$ & $\mathrm{C}$ & Total \\
$(281)$ & $(118)$ & $(101)$ & \\
\hline It will reduce pollution material emitted on the road & 4.16 & 3.98 & 3.94 & 4.07 \\
\hline It will be cost-saving & 4.56 & 4.21 & 4.39 & 4.44 \\
\hline It will resolve city traffic congestion & 4.16 & 3.85 & 3.95 & 4.04 \\
\hline It will reduce the number of bus and public transit \\
users & 3.86 & 3.78 & 3.97 & 3.87 \\
\hline It will reduce the number of taxi users & 4.55 & 3.98 & 4.30 & 4.37 \\
\hline It will reduce the use of personal passenger cars & 4.26 & 3.48 & 3.94 & 4.01 \\
\hline It will make my travel more convenient & 4.70 & 3.36 & 4.46 & 4.34 \\
\hline It will reduce my travel time & 4.57 & 3.30 & 4.30 & 4.21 \\
\hline It will make my travel more fun & 4.19 & 2.94 & 4.30 & 3.92 \\
\hline It will make my travel more pleasant & 4.29 & 3.02 & 4.44 & 4.02 \\
\hline
\end{tabular}

*A: A group that has not used the service but has a willingness to use it in the future.

*B: A group that has not used the service and never will.

$* \mathrm{C}$ : A group that has used the service before. 
in terms of environmental issues, cost-saving effects and solutions to city traffic congestion issues in comparison with group $\mathrm{C}$ which has experience to use the service. In addition, it was also group A who showed the highest score on question items stating that the number of taxi users would go down as people started to use car-sharing services.

However, group $\mathrm{C}$, which has experienced using the service, shows the highest average scores to the question item as to if using car-sharing will make their travel more pleasant. This is because private companies in Busan such as SoCar and GreenCar have relatively good maintenance which gives a high level of satisfaction to the users.

\subsection{Study on the revitalization of shared transportation}

According to the survey conducted for this study, $20.2 \%$ of the 500 respondents total turned out to have used the car-sharing service and to be sensitive about reservations, rent, return, and rate of vehicles. Therefore, it is vital that policies regarding discounts and securing carsharing parking lots, facilitating the renting and returning of cars, be taken into consideration to revitalize shared transportation through car-sharing services in the public sector in the future.

There were 281 out of 399 respondents who have not used the service before that expressed their intention to use the service in the future. Group B - people who have not used the service and never will - is relatively not interested in car-sharing. However, a total of $70.4 \%$ of respondents have shown their willingness to use the service in the future and it confirms the possibility of reducing personal passenger cars through the revitalization of shared transportation.

Group A in particular showed their tendency to be sensitive about the method of returning the vehicle. Although SoCar has zones within which drivers can return their cars to the location they want, several cities, including Busan, still lack enough space to accommodate car sharing vehicles. Therefore, it is necessary prioritize securing enough space for carsharing vehicles at a public policy-making level.

Most of all, the rearrangement of laws related to this issue must be followed up on. It is crucial to set up legal and institutional definitions and rules for shared transportation such as car-sharing and ride-sharing. It also requires reviewing the existing laws related to shared transportation, such as The Passenger Transport Service Act and The Parking Lot Act.

On top of that, it is vital to pursue profits and interests for the good of the community in realizing shared services in the transportation sector. Therefore, public organizations must be at the centre of the policy-making process in a way that shared transportation become adopted as a policy. It is necessary to adopt shared transportation services, studies and policies that fit geographical features, city planning, and the connectivity to existing public transportation of each city.

\section{CONCLUSION}

The purpose of this study is to look into the perceptions of people towards car-sharing and examine them, dependent on their experiences using car-sharing services, finding solutions to boost shared transportation. To do this, domestic policies, trends, and studies related to car-sharing were reviewed through previous studies and documents. Based on this review, question items were created to conduct a survey for citizens divided into three different groups and the results of this survey were found.

First, as a result of the survey conducted for the citizens of Busan, it turned out that $20 \%$ of respondents have used car-sharing and more than $50 \%$ of respondents who have not used 
the service gave positive answers when they were asked whether they have any intention to use the service in the future.

Second, the rate of the service turned out to be the most important item in the group with experience using the service when the level of importance-satisfaction was surveyed. Reservations and renting cars are the items that need to be improved upon. On the contrary, respondents do not think that it is important to have tax benefits, incentives or PR from using the service.

Thirdly, a binary logistic regression analysis was performed for the group who has not used the service before but is willing to use the service in the future. It turned out that the method of returning the vehicle was the most important item to this group. It is urgent to secure some space for car-sharing services because people prefer to return vehicles to their desired location four times more than having to return vehicles to the rental location.

In order to resolve traffic issues in the city, it is important to actively review alternative transportation that can provide door to door service from departure to arrival and car-sharing services can make this happen. Most of all, active leadership from the public sector is required to realize "sharing" in the transportation sector. To do this, it is imperative to legislate and rearrange laws related to this area and to come up with studies to develop the shared transportation policies that fit the characteristics of the local area.

This study was conducted towards a specific city and area and it is necessary to have a follow up study to analyse the preferences of many people from many different places. It is important to do an empirical study as soon as possible about solutions to boost sharing, such as bike-sharing, parking sharing, and PM (personal mobility).

\section{ACKNOWLEDGEMENT}

This research was supported by Basic Science Research Program through the National Research Foundation of Korea (NRF) funded by the Ministry of Education (2015R1D1A1A01060403).

\section{REFERENCES}

[1] Martin, E.W. \& Shaheen, S.A., Greenhouse gas emission impacts of carsharing in North America. IEEE Transactions on Intelligent Transportation Systems, 12(4), pp. 1074-1086, 2011. DOI: 10.1109/tits.2011.2158539.

[2] Shaheen, S.A., Cohen, A.P. \& Roberts, J.D., Carsharing in North America: Market growth, current developments, and future potential. Transportation Research Record. Journal of the Transportation Research Board, 1986(1), pp. 16-124, 2006.

DOI: 10.3141/1986-17.

[3] Meijkamp, R., Changing consumer behaviour through eco-efficient services: An empirical study of car sharing in The Netherlands. Business Strategy and the Environment, 7(4), pp. 234-244, 1998.

DOI: 10.1002/(sici)1099-0836(199809)7:4<234::aid-bse159>3.0.co;2-a.

[4] Millard-Ball, A., Murray, G., Schure, J.T., Fox, C. \& Burkhardt, J., Car-sharing: Where and How it Succeeds, vol. 108, Transit Cooperative Research Program, Transportation Research Board, pp. 1-264, 2005.

[5] Illgen, S. \& Höck, M., Electric vehicles in car sharing networks - Challenges and simulation model analysis. Transportation Research Part D: Transport and Environment, 63, pp. 377-387, 2018. DOI: 10.1016/j.trd.2018.06.011.

[6] Namazu, M., MacKenzie, D., Zerriffi, H. \& Dowlatabadi, H., Is carsharing for everyone? Understanding the diffusion of carsharing services. Transport Policy, 63, pp. 189-199, 2018. DOI: 10.1016/j.tranpol.2017.12.012. 
[7] Seoul Institute, Policy Report, No.197, 2015.

[8] Seoul Metropolitan Government, 2016. Online. www.seoul.go.kr.

[9] Kim, S.H. \& Lee, K.J., The impact of public transit accessibility on the car-sharing use demand. The Korea Institute of Intelligent Transport Systems, 15(4), pp. 1-11, 2016. DOI: $10.12815 /$ kits.2016.15.4.001.

[10] Seo, J.M. \& Sheok, C.S., A study on optimizing depot location in carsharing considering the neighborhood environmental factors. The Korea Institute of Intelligent Transport Systems, 16(5), pp. 49-59, 2017. DOI: 10.12815/kits.2017.16.5.49.

[11] Jang, J.S. \& Rho, J.H., A study on introduction and activation plan of P2P car sharingfor the apartment complex in Seoul. Journal of the Korea Academia-Industrial Cooperation Society, 18(2), pp. 47-60, 2017. 